\title{
Comparison of the PI3KCA pathway in circulating tumor cells and corresponding tumor tissue of patients with metastatic breast cancer
}

\author{
MAREN BREDEMEIER ${ }^{1}$, SABINE KASIMIR-BAUER ${ }^{1}$, HANS-CHRISTIAN KOLBERG ${ }^{2}$, \\ THOMAS HEROLD ${ }^{3}$, SARAH SYNORACKI ${ }^{3}$, SIEGFRIED HAUCH ${ }^{4}$, PHILIPPOS EDIMIRIS $^{1}$, \\ AGNES BANKFALVI $^{3}$, MITRA TEWES ${ }^{5}$, RAINER KIMMIG ${ }^{1}$ and BAHRIYE AKTAS ${ }^{1}$
}

\footnotetext{
${ }^{1}$ Department of Gynecology and Obstetrics, University Hospital Essen, University of Duisburg-Essen, D-45122 Essen;

${ }^{2}$ Department of Gynecology and Obstetrics, Marienhospital Bottrop, D-46236 Bottrop; ${ }^{3}$ Institute of Pathology,

University Hospital Essen, University of Duisburg-Essen, D-45122 Essen;

${ }^{4}$ Qiagen Hannover GmbH, D-30853 Langenhagen; ${ }^{5}$ Department of Medical Oncology, West German

Cancer Center, University Hospital Essen, University of Duisburg-Essen, D-45122 Essen, Germany
}

Received September 19, 2016; Accepted December 19, 2016

DOI: $10.3892 / \mathrm{mmr} .2017 .6415$

\begin{abstract}
The aim of the present study was to compare the phosphatidylinositol3-kinase(PI3KCA)-AKT serine/threonine kinase (AKT) pathway in circulating tumor cells (CTCs) and corresponding cancerous tissues. Stemness-like circulating tumor cells (slCTCs) and CTCs in epithelial-mesenchymal transition (EMT) have been implicated as the active source of metastatic spread in breast cancer (BC). In this regard, the PI3KCA-AKT signaling pathway was demonstrated to be implicated in and to be frequently mutated in $\mathrm{BC}$. The present study compared this pathway in slCTCs/CTCs in EMT and the corresponding tumor tissues of 90 metastatic BC patients (pts). slCTCs and CTCs in EMT were isolated using the AdnaTest EMT-1/StemCell for the detection of aldehyde dehydrogenase 1 family member A1 (ALDH1) (singleplex PCR) and PI3KCA, AKT2 and twist family bHLH transcription factor 1 (multiplex PCR). Tumor tissue was investigated for PI3KCA hotspot mutations using Sanger sequencing of genomic DNA from
\end{abstract}

Correspondence to: Dr Bahriye Aktas, Department of Gynecology and Obstetrics, University Hospital Essen, University of Duisburg-Essen, 55 Hufelandstrasse, D-45122 Essen, Germany E-mail: bahriye.aktas@uk-essen.de

Abbreviations: CTCs, circulating tumor cells; slCTCs, stemness-like CTCs; EMT, epithelial-mesenchymal transition; BC, breast cancer; PFS, progression-free survival; OS, overall survival; mTOR, mechanistic target of rapamycin; ER, estrogen receptor; PR, progesterone receptor; pts, patients; HER2, human epidermal growth factor receptor 2

Key words: circulating tumor cells, epithelial-mesenchymal transition, phosphatidylinositol 3-kinase-AKT signaling pathway, PI3KCA mutation, phosphatase and tensin homolog loss, metastatic breast cancer, liquid biopsy micro-dissected formalin-fixed paraffin-embedded tissue, and for the expression of ALDH1 and phosphorylated AKT (pAKT), and phosphatase and tensin homolog (PTEN) loss, by immunohistochemistry. slCTCs were identified in $23 \%$ of pts (21/90 pts) and CTCs in EMT in 56\% (50/90 pts) of pts. pAKT and ALDH1 positivity in tumor tissue was identified in 47 and $9 \%$ of cases, respectively, and a PTEN loss was observed in $18 \%$ of pts. A significant association was detected between pAKT expression in cancerous tissue and AKT2 expression in CTCs $(\mathrm{P}=0.037)$. PI3KCA mutations were detected in $32 \%$ of pts, most frequently on exons 21 (55\%) and 10 (45\%). Pts with PI3KCA mutations in tumor tissue had a significantly longer overall survival than pts with wild-type PI3KCA expression ( $\mathrm{P}=0.007)$. Similar results were obtained for pts with aberrant PI3KCA signaling in CTCs and/or aberrant signaling in cancerous tissue $(\mathrm{P}=0.009)$. Therapy-resistant CTCs, potentially derived from the primary tumor or metastatic tissue, may be eliminated with specific PI3K pathway inhibitors, alone or in combination, to improve the prognosis of metastatic $\mathrm{BC}$ pts.

\section{Introduction}

Stem cell-like tumor cells have been implicated as the active source of metastatic spread in breast cancer (BC). To disseminate and metastasize, these cells may undergo phenotypic changes, known as epithelial-mesenchymal-transition (EMT) (1-3). The phosphatidylinositol3-kinase(PI3KCA)-AKT serine/threonine kinase (AKT) signaling pathway has been identified as one of the most important and most frequently mutated pathways involved in these processes. In BC, PI3KCA mutations are frequently detected, most commonly in exon 10 (E454K and E424K) and exon 21 (H1047R), which encode the helical and kinase domain $(4,5)$. Whereas mutations in the helical domain remove the interaction between $\mathrm{p} 85$ and p110, leading to constitutive PI3KCA activity, mutations in the kinase domain directly affect the catalytic subunit of PI3KCA 
by allosteric changes, allowing easier access of the substrate to the catalytic site $(6,7)$. PI3KCA mutations in tumor tissue have previously been investigated in $\mathrm{BC}$, resulting in contradictory results with regard to progression-free survival (PFS) and overall survival (OS) (8-13). New treatment strategies for BC are currently being developed, which target molecular targets that are thought to contribute to the disease. These therapies include inhibitors of the PI3KCA-AKT pathway mechanistic target of rapamycin (mTOR), which is closely associated with estrogen receptor (ER) signaling (14). In this regard, the mTOR inhibitor everolimus, in combination with exemestane, has been demonstrated to improve the PFS in patients (pts) with advanced BC (15). Archival tumor samples from pts in the BOLERO-1 (clinical trials.gov identifier NCT00876395) and BOLERO-3 (clinical trials.gov identifier NCT01007942) trials were analyzed using next-generation sequencing, immunohistochemistry and Sanger sequencing. This analysis suggested that pts that had human epidermal growth factor receptor 2 (HER2)-positive advanced BC with PI3KCA mutations, phosphatase and tensin homolog (PTEN) loss, or a hyperactive PI3KCA pathway in the tumor may derive PFS benefit from the application of everolimus (16). In the BOLERO-1 trial, pts were randomly assigned to receive either everolimus (10 mg) once a day orally or a placebo plus weekly intravenous administration of trastuzumab and paclitaxel. The BOLERO-1 trial revealed that the addition of everolimus to trastuzumab plus paclitaxel treatment did not improve clinical outcomes in the entire population: Median PFS was 15 months with everolimus arm vs. 14 months with placebo arm (HR 0.89; P=0.11) (17). In the hormone receptor-negative subpopulation, the median PFS in the everolimus arm of the study was 20 months compared with 13 months in the placebo arm (HR 0.66; $\mathrm{P}=0.004)$. A clinically relevant prolongation of PFS following the addition of everolimus in hormone receptor negative pts up to 7 months may be achieved. Further BOLERO trials demonstrated beneficial effects when everolimus was added to endocrine treatment (BOLERO-2; clinical trials.gov identifier NCT00863655), or to trastuzumab and vinorelbine treatment of taxane-pretreated advanced BC pts that were trastuzumab resistant (BOLERO-3; clinical trials.gov identifier NCT01007942) (18). Additionally, the PI3K inhibitor, BKM120 also termed burparlisib, was demonstrated to be effective in combination with fulvestrant in hormone receptor-positive advanced BC pts that were resistant to hormonal treatment and harbored PI3KCA mutations (BELLE-2 study; clinical trials.gov identifier NCT01610284). The PFS for pts that received fulvestrant alone was 5 months, whereas the pts that received buparlisib plus fulvestrant had a PFS of 6.9 months (HR 0.78; P<0.001). Pts had improved outcomes, with a PFS of 7 months, if they received buparlisib plus fulvestrant when mutant PI3KCA was detected in their circulating tumor DNA (ctDNA), compared with pts who received fulvestrant alone, with a PFS of 3.2 months (HR 0.56; $\mathrm{P}<0.001)(19)$. For each new targeted therapy, a biomarker may help to match the appropriate drug to the appropriate pts. In this context, the characterization of stemness-like circulating tumor cells (slCTCs) and CTCs in EMT for such biomarkers may be important in the future, as metastatic tissue is often difficult to obtain. SICTCs and CTCs in EMT have already been identified in the heterogeneous population of CTCs of metastatic and primary BC pts (20-25). In addition, it is important to note that the expression of predictive markers, including hormonal receptors, such as HER2, may change during disease progression or treatment, resulting in ineffective treatment (26-30). Taking into account that the PI3KCA pathway is involved in the survival of slCTCs and CTCs in EMT, the present study compared this pathway in slCTCs and CTCs in EMT of 90 metastatic BC pts, at the time of disease progression or at the time of relapse of previously diagnosed $\mathrm{BC}$, and the corresponding tumor tissues. For this purpose, blood was analyzed for CTCs overexpressing EMT markers (PI3KCA $\alpha$ and AKT2) and sICTC markers [aldehyde dehydrogenase 1 family member A1 (ALDH1)]. In addition, corresponding tumor tissue was analyzed for the expression of phosphorylated AKT (pAKT), ALDH1, PTEN loss and PI3KCA hotspot mutations. The aim of the current study was to elucidate whether blood samples may serve as a reliable source to determine the optimal use of targeted therapies in the future.

\section{Materials and methods}

Patient population and characteristics. The study was conducted at the Department of Gynecology and Obstetrics in collaboration with the Department of Internal Medicine (Cancer Research) and the Institute of Pathology at the University Hospital Essen (Essen, Germany). Between July 2011 and September 2015, 90 metastatic BC pts, aged between 38 and 77, were enrolled for blood and tissue analysis. In total, 40 primary tumors, 44 visceral and 15 non-visceral metastases were available for analysis. Pts had already received more than one palliative endocrine, chemo-, antibody- or experimental therapy, the majority had received more than the third-line therapy. Initial biopsy of the primary tumors revealed ER positivity in $85 \%$, progesterone receptor positivity in $64 \%$ and HER 2 positivity in $20 \%$ of pts, while $11 \%$ of pts were triple-negative. The receptor status of seven pts was unknown.

Eligibility criteria. The eligibility criteria were as follows: Age, $\geq 18$ years; measurable or evaluable metastatic BC; predicted life expectancy, $\geq 2$ months; Eastern Cooperative Oncology Group (ECOG) scores for performance status of 0-2; no severe, uncontrolled co-morbidities or medical conditions; and no second malignancies. ECOG status is a good predictor of survival, prognosis and response to treatment, which facilitates decision-making in oncology (31). Pts had either a relapse of $\mathrm{BC}$ diagnosed in the past and were to start chemotherapy, or a documented progressive BC before receiving a new endocrine, chemo- or experimental therapy. Prior adjuvant treatment, radiation or any other treatment of metastatic disease was permitted. Exclusion criteria were other malignancies except BC. All specimens were obtained after written informed consent and collected using protocols approved by the institutional review board.

Sampling of blood. EDTA blood $(2 \times 5 \mathrm{ml})$ was collected for isolation of CTCs with an S-Monovette ${ }^{\circledR}$ (Sarstedt AG \& Co., Nümbrecht, Germany) and stored at $4^{\circ} \mathrm{C}$ until further examination. The samples were processed immediately or no longer than $4 \mathrm{~h}$ after blood withdrawal. 
Collection of tumor samples. A small sample of the primary tumor was taken from pts who underwent surgery or tumor biopsy for medical reasons, or as part of a research treatment protocol. Samples of metastases were taken by needle biopsy combined with an imaging procedure, such as computerized tomography, magnetic resonance imaging or ultrasound.

Detection of slCTCs and CTCs in EMT. Both subtypes of CTCs were investigated by positive immunomagnetic selection using AdnaTest EMT-1/StemCell (Qiagen GmbH, Hilden, Germany). RNA was recovered and reverse transcribed for analysis using the AdnaTest EMT-1 [multiplex reverse transcription-polymerase chain reaction (RT-PCR) for twist family bHLH transcription factor 1 (TWIST1), AKT2 and PI3KCA $\alpha$ ], and the AdnaTest TumorStemCell (Qiagen $\mathrm{GmbH}$; singleplex RT-PCR for ALDH1). Identification of EMT markers was considered positive if at least one of the three markers was detected in the sample. The assay was performed according to the manufacturer's protocol and has been described in detail elsewhere (20).

Embedding of tumor tissue samples. Routinely formalin-fixed and paraffin embedded tumor tissue blocks were retrieved from the archives of the Institute of Pathology of the University Hospital Essen, Essen, Germany. Paraffin processing of tumor tissues was performed according to established protocols for routine histopathology. For fixation, $10 \%$ neutral buffered formalin ( $4 \%$ formaldehyde) was used at room temperature for $24 \mathrm{~h}$ up to $48-72 \mathrm{~h}$. For immunohistochemistry, $4 \mu \mathrm{m}$ thick paraffin sections were cut and mounted on SuperFrost ${ }^{\circledR}$ Plus slides (Menzel-Gläser, Braunschweig, Germany).

Evaluation of PTEN loss, pAKT and ALDH1 expression. PTEN loss, pAKT and ALDH1 expression were investigated using immunohistochemistry. At all times, the manufacturer's protocol was followed. pAKT was determined using Ser473 rabbit polyclonal antibody (diluted 1:100; cat. no. sc-7985-R; Santa Cruz Biotechnology, Inc., Dallas, TX, USA) and detected on the Benchmark Ultra (Ventana Medical Systems, Inc., Tucson, AZ, USA) using the OptiView DAB IHC detection kit (Roche Diagnostics, Basel, Switzerland). ALDH1 staining was performed using the aa-7-128 monoclonal mouse antibody (diluted 1:2,000; cat. no. 611194; BD transduction Laboratories $^{\mathrm{TM}}$; BD Biosciences, San Jose, CA, USA) and the Zytomed polymer DAB detection system (Zytomed Systems $\mathrm{GmbH}$, Berlin, Germany) followed by staining on the DAKO Autostainer (Dako; Agilent Technologies, Inc., Santa Clara, CA, USA). PTEN was detected using 138G6 rabbit monoclonal antibody (diluted 1:200; cat. no. 9559S; Cell Signaling Technology, Inc., Danvers, MA, USA) and staining was performed on the full-automatic Ultra Bench Mark (Ventana Medical Systems, Inc.) using the PTEN OptiView DAB IHC detection kit (Roche Diagnostics). In addition, immunohistochemical analysis of the primary tumor with regard to the tumor type, TNM-staging, histology and grading were assessed in the Department of Pathology of the University Hospital Essen. IHC staining was evaluated according to the H-score scoring system, taking into account the percentage of staining intensity (0-3). The H-score is defined as the product of $3 x$ the percentage of strongly stained nuclei $+2 \mathrm{x}$ the percentage of moderately stained nuclei + the percentage of weakly stained nuclei $\left[1 \mathrm{x}\left(\%\right.\right.$ cells $\left.1^{+}\right)+2 \mathrm{x}\left(\%\right.$ cells $\left.2^{+}\right)+3 \mathrm{x}\left(\%\right.$ cells $\left.\left.3^{+}\right)\right]$, giving a range of 0 to 300 , as a continuous variable. An $\mathrm{H}$-score of $3^{+}$ was classed as a strong, $2^{+}$as medium and $1^{+}$as weak staining. A complete absence of staining was indicated by a $\mathrm{H}$-score of 0 (32). Tumor-free breast tissue served as control for all markers. A staining result was considered to be positive for ALDH1 and pAKT if the H-score was higher than the reference staining of non-malignant breast tissue, which served as a control. PTEN loss was defined as the complete absence of PTEN staining.

DNA extraction from formaldehyde-fixed paraffin-embedded tissue. Five tissue cores of $0.9 \mathrm{~mm}$ in size (Terumo Medical Corporation, Tokyo, Japan), containing $\geq 50 \%$ tumor cells, were prepared under supervision of a trained pathologist and stored in BIOPUR tubes (Eppendorf, Hamburg, Germany). For paraffin removal, $320 \mu \mathrm{l}$ of deparaffinization solution (Qiagen $\mathrm{GmbH}$ ) was added, vortexed for $10 \mathrm{sec}$, incubated at $56^{\circ} \mathrm{C}$ for $3 \mathrm{~min}$ and cooled to room temperature. DNA extraction was performed with the QIAmp DNA formalin-fixed paraffin-embedded kit (Qiagen $\mathrm{GmbH}$ ) according to the manufacturer's instructions. After incubation for $5 \mathrm{~min}$ at $19^{\circ} \mathrm{C}$, DNA was generated by centrifugation for $1 \mathrm{~min}$ at $20,000 \mathrm{x}$. The DNA concentration was assessed using NanoDrop Technology (Thermo Fisher Scientific, Inc., Pittsburgh, PA, USA) and stored at $4^{\circ} \mathrm{C}$ until further usage.

Detection of PI3KCA mutations. Target specific PCR was performed using AmpliTaq gold polymerase (Thermo Fisher Scientific, Inc., Waltham, MA, USA). A master mix $(50 \mu \mathrm{l})$ was prepared with DNAse-free $\mathrm{H}_{2} \mathrm{O}(36 \mu \mathrm{l}), 10 \mathrm{X}$ buffer $(5 \mu \mathrm{l})$, $25 \mathrm{mM} \mathrm{MgCl}_{2}(5 \mu \mathrm{l}), 10 \mathrm{mM}$ dNTP mix $(1 \mu \mathrm{l})$, AmpliTaq gold polymerase $(0.5 \mu \mathrm{l})$ and $10 \mathrm{pmol} / \mu \mathrm{l}$ primer mix $(0.5 \mu \mathrm{l})$. For initial DNA concentrations between 5-50 ng/ $\mu \mathrm{l}, 2 \mu \mathrm{l}$, and for concentrations between $51-100 \mathrm{ng} / \mu \mathrm{l}, 1 \mu \mathrm{l}$ of the undiluted DNA was used. For DNA concentrations $>100 \mathrm{ng} / \mu \mathrm{l}$, a dilution was performed (final concentration 51-100 $\mathrm{ng} / \mu \mathrm{l}$ ). The PI3KCA forward $(\mathrm{F})$ and reverse $(\mathrm{R})$ primer sequences were as follows (sequencing adapters are underlined): Exon 10 F: TATGTAAAACGACGGCCAGTACAGCTCAAAGCA ATTTCTACACG, Exon 10 R: TATTATAGGGCGAAT TGGGTTCTCCATTTTAGCACTTACCTGTGAC, Exon 21 F: TATGTAAAACGACGGCCAGTGATGCTTGGCTCT GGAATGC, Exon 21 R: TATTATAGGGCGAATTGGGTT CTTTTCAGTTCAATGCATGCTG10.

Exon specific PCR was performed on a thermal cycler starting at $95^{\circ} \mathrm{C}$ for $5 \mathrm{~min}$, followed by 15 cycles of $95^{\circ} \mathrm{C}$ $(20 \mathrm{sec}), 59^{\circ} \mathrm{C}(1 \mathrm{~min})$ and $72^{\circ} \mathrm{C}(30 \mathrm{sec})$, and 35 cycles of $95^{\circ} \mathrm{C}(20 \mathrm{sec}), 52^{\circ} \mathrm{C}(1 \mathrm{~min})$ and $72^{\circ} \mathrm{C}(1 \mathrm{~min})$. PCR products were verified on Agilent Bioanalyzer (Agilent Technologies, Inc.) with fragment sizes of $137 \mathrm{bp}$ (exon 10) or $241 \mathrm{bp}$ (exon 21) in length. Digestion of PCR primers and single stranded DNA was performed using exonuclease 1 (New England BioLabs, Inc., Ipswich, MA, USA) and antarctic phosphatase (New England BioLabs, Inc.). Digestion was performed in the Primus 25 advanced ${ }^{\circledR}$ (Peqlab; VWR International, Radnor, PA, USA) or Biometra T3000 thermal cycler (Biometra $\mathrm{GmbH}$, Göttingen, Germany) for $30 \mathrm{~min}$ at $37^{\circ} \mathrm{C}$, followed by $15 \mathrm{~min}$ at $72^{\circ} \mathrm{C}$. Exodigested products were frozen at 
$-20^{\circ} \mathrm{C}$ for further usage. The BigDye Terminator Seq. $3.1 \mathrm{kit}$ (Thermo Fisher Scientific, Inc.) was used for cycle sequencing. Each purified PCR product $(1 \mu \mathrm{l})$ was added to the prepared mastermixes containing either the P172-forward or the M1320-reverse primer (Biolegio, Nijmegen, Netherlands). The universal primer sequences were as follows: M13-20: GTA AAACGACGGCCAGT, P172: TATAGGGCGAATTGGGT. Cycle sequencing was carried out in the Primus 25 advanced or Biometra T3000 thermal cycler as follows: $10 \mathrm{sec}$ at $95^{\circ} \mathrm{C}$, followed by 25 cycles of $5 \mathrm{sec}$ at $50^{\circ} \mathrm{C}$ and $2 \mathrm{~min}$ at $60^{\circ} \mathrm{C}$. Cycle sequencing products were frozen at $-20^{\circ} \mathrm{C}$ for further usage. After ethanol precipitation, sequencing was performed on the 3500 Genetic Analyzer (Applied Biosystems; Thermo Fisher Scientific, Inc.). Mutation analysis was performed with the Sequencher software version 5.1 (Gene Codes Corporation, Ann Harbor, MI, USA).

Statistical analysis. Statistical analysis was performed using Winstat (2012.1), an upgrade of Microsoft Excel (www.winstat.de). Survival intervals were screened from the time of CTCs analysis until the date of mortality and calculated with Kaplan-Meier estimator (Log-rank test). Association of CTCs and tissue results were performed by contingency tables, displaying the frequency distribution of two variables (marker expression in CTC vs. marker expression in tissue). P-values were generated with the $\chi^{2}$ test; if less than five cases were identified in each group, Fisher's exact test was used. $\mathrm{P}<0.05$ was considered to indicate a statistically significant difference.

\section{Results}

Expression of EMT and stem cell markers in CTCs. As presented in Fig. 1, CTCs in EMT were detected in 50/90 pts (56\%), expression of PI3KCA $\alpha$ was detected in 38/90 (42\%), AKT2 in 40/90 (44\%) and TWIST1 in 2/90 pts (2\%). slCTCs were identified in $21 / 90$ pts $(23 \%)$, and $20 / 90$ pts $(22 \%)$ had sICTCs and CTCs in EMT. Of the 90 pts, 39 had neither slCTCs nor CTCs in EMT.

Expression of EMT and stem cell markers in tumor tissue. Representative staining for the expression of ALDH1, pAKT and PTEN are illustrated in Fig. 2. PTEN staining was possible in $85 / 90$ pts and PTEN loss was detected in $15 / 85$ pts (18\%). Staining of pAKT and ALDH1 was performed in 34/90 pts and positive results were detected in 16/34 pts (47\%) and $3 / 34$ pts (9\%), respectively (Fig. 3). PI3KCA mutations were assessed in all 90 pts and were detected in 29/90 pts (32\%). Mutations were identified most frequently on exon $21(55 \%$, $16 / 29$ pts) with the H1047R mutation detected in 14/16 pts (87\%), and the H1047L mutation in 2/16 pts with mutations on exon $21(13 \%)$. Among the pts with a mutation on exon 10 $(13 / 29,45 \%)$, the E545K mutation was detected in $9 / 13$ pts (69\%), the E542 K mutation in 3/13 pts (23\%) and the mutation c.1615C $>$ T p.Pro539Ser in one patient (Fig. 4).

Comparison of PI3KCA mutations in tumor tissue and PI3KCA $\alpha$ expression in CTCs. The comparison of PI3KCA mutations in tumor tissue and the expression of PI3KCA $\alpha$ in CTCs was performed in all 90 pts and is presented in Table I. Whereas 36 pts had wild-type PI3KCA in tumor tissue and no
Table I. Association of PI3KCA mutations in tumor tissue and PI3KCA $\alpha$ expression in CTCs. Number of pts with each tissue PI3KCA type and CTC phenotype.

\begin{tabular}{lcc}
\hline & \multicolumn{2}{c}{ CTC phenotype } \\
\cline { 2 - 3 } Tumor tissue & PI3KCA $\alpha-C T C s$ & PI3KCA $\alpha+$ CTCs \\
\hline PI3KCA wild type & 36 & 25 \\
PI3KCA mutation & 16 & 13 \\
\hline
\end{tabular}

$\mathrm{n}=90$ pts; $\mathrm{P}=0.730$ ( $\chi^{2}$ test). PI3KCA, phosphatidylinositol 3-kinase; CTCs, circulating tumor cells; pts, patients.

Table II. Association of pAKT expression in tumor tissue and AKT2 expression in CTCs. Number of pts with each pAKT status and CTC phenotype.

\begin{tabular}{lcc}
\hline & \multicolumn{2}{c}{ CTC phenotype } \\
\cline { 2 - 3 } Tumor tissue & AKT2-CTCs & AKT2+ CTCs \\
pAKT status & 11 & 7 \\
pAKT- & 4 & 12 \\
pAKT+ & 4 \\
\hline
\end{tabular}

$\mathrm{n}=34$ pts; statistical analysis with contingency tables (Fisher's exact test) did show a significant correlation between pAKT status of tumor tissue and AKT2 expression in CTC of the same pts $\mathrm{P}=0.037$. pAKT, phosphorylated AKT serine/threonine kinase; CTCs, circulating tumor cells; pts, patients.

PI3KCA $\alpha$ expression in CTCs, 13 pts had PI3KCA mutations in tumor tissue and PI3KCA $\alpha$ expression in CTCs. Only 16 pts had PI3KCA mutations in tumor tissue with no PI3KCA $\alpha$ expression in CTCs, whereas in 25 pts the results were opposite, with wild-type PI3KCA in tumor tissue and PI3KCA $\alpha$ expression detected in CTCs. No significant association between PI3KCA mutations in tumor tissue and the expression of PI3KCA $\alpha$ in CTCs was demonstrated $(\mathrm{P}=0.730)$.

Comparison of AKT expression in tumor tissue and CTCs. The comparison of pAKT staining and AKT2 expression in CTCs was performed in 34/90 pts and is presented in Table II. Whereas 12 pts were AKT2-positive in tumor tissue and CTCs, negative results in both features were obtained for 11 pts. In 4 pts, AKT expression was only detected in tumor tissue, and in 7 pts AKT was only detected in CTCs. The expression of pAKT in cancerous tissue was significantly associated with the presence of AKT2 expressing CTCs $(\mathrm{P}=0.037)$.

Comparison of ALDH1 expression in tumor tissue and the presence of slCTCs. The comparison of ALDH1 in tumor tissue and CTCs was performed in 34/90 pts and is presented in Table III. Overall, 2 pts were positive/positive for ALDH1 expression in tumor tissue and the presence of slCTCs; 1 patient was negative/negative. Additionally, 8 pts were only slCTC positive and 1 was only ALDH1-positive. Thus, there 


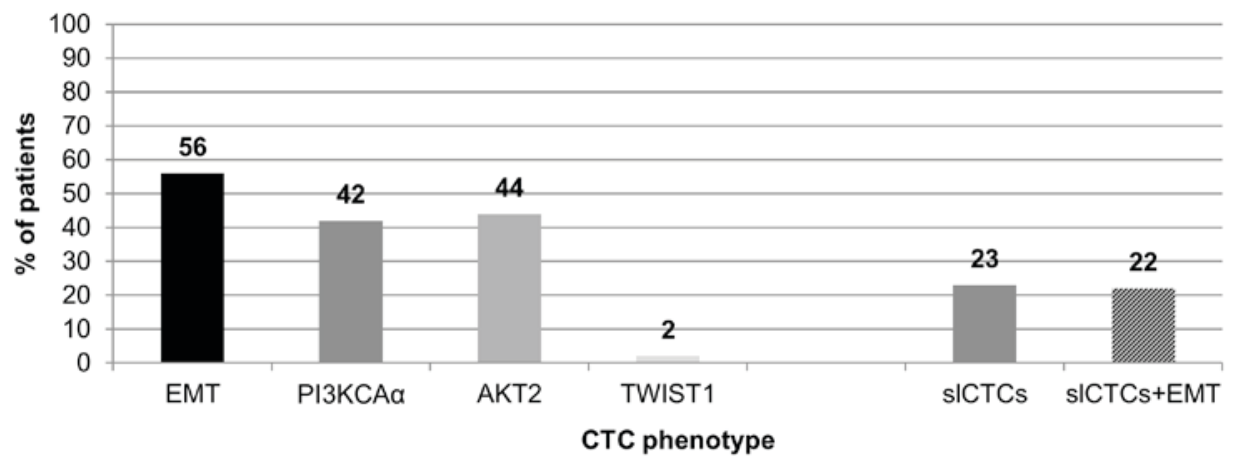

Figure 1. Expression of EMT and stem cell markers in CTCs (n=90 pts). CTCs in EMT were detected in 56\% of pts, including PI3KCA $\alpha$ expression (42\%), AKT2 (44\%) and TWIST1 (2\%). SlCTCs were detected in 23\% of the pts, whereas 22\% had slCTCs, and CTCs in EMT. Pts, patients; EMT, epithelial-mesenchymal transition; PI3KCA $\alpha$, phosphatidylinositol 3-kinase $\alpha$; AKT2, AKT serine/threonine kinase 2; TWIST1, twist family bHLH transcription factor 1; CTCs, circulating tumor cells; slCTCs, stemness-like CTCs.
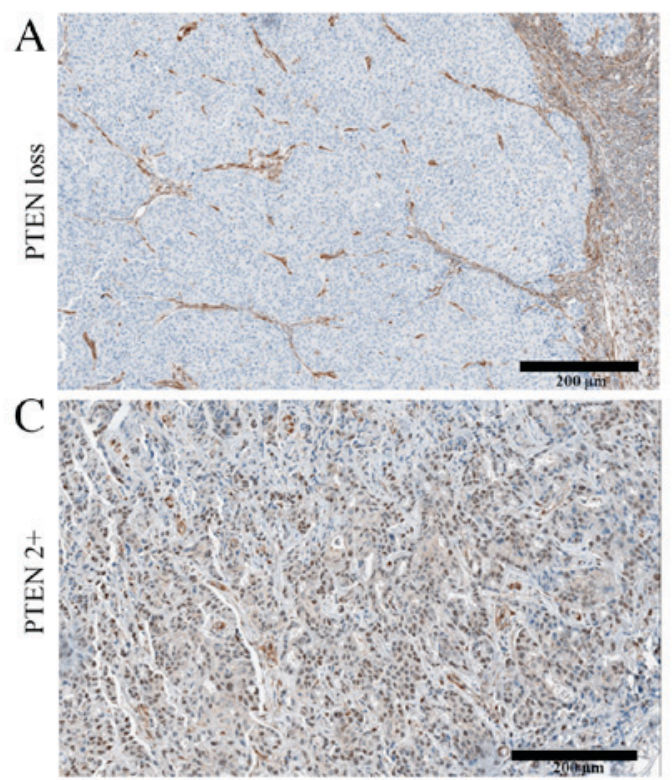

E

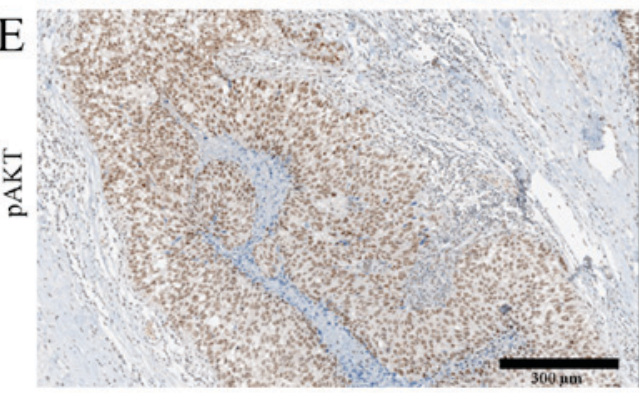

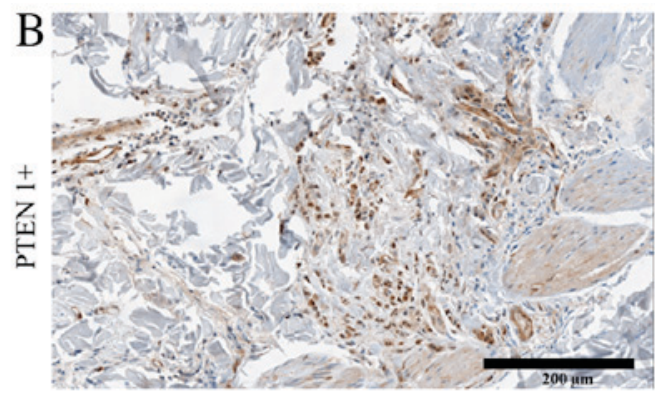

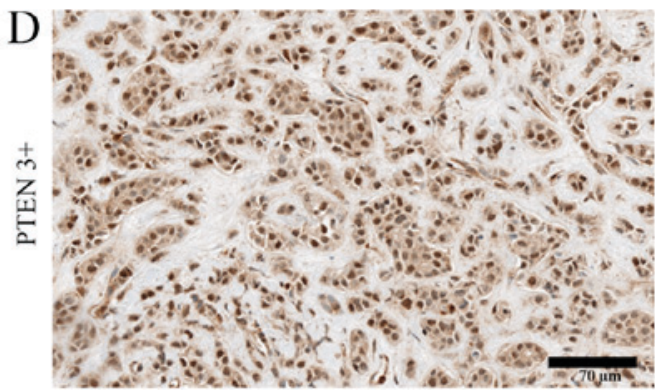

\section{$\mathrm{F}$}

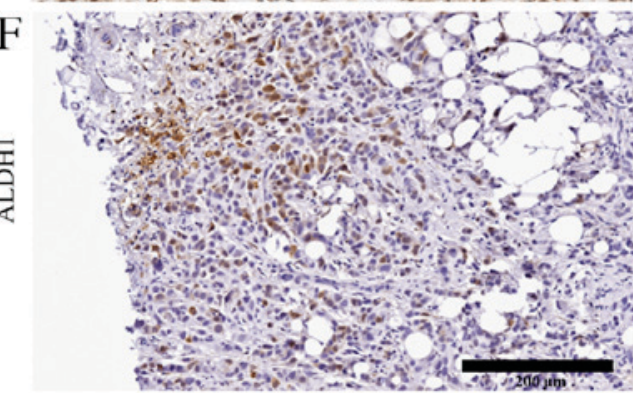

Figure 2. Representative staining of PTEN, pAKT and ALDH1 in cancerous tissues. Results for PTEN are presented according to the staining intensities and correspond to (A) PTEN loss, (B) low PTEN expression, 1+, (C) moderate PTEN expression, 2+ and (D) intense PTEN expression, 3+. (E) pAKT expression and (F) ALDH1 expression. PTEN, phosphatase and tensin homolog; pAKT, phosphorylated AKT serine/threonine kinase; ALDH1, aldehyde dehydrogenase 1 family member A1.

was no significant correlation between ALDH1 expression and the presence of slCTCs $(\mathrm{P}=0.200)$.

Comparison of an aberrant PI3KCA pathway in tissue and CTCs. For CTCs, a patient had an aberrant PI3KCA pathway if ALDH1 and/or one of the EMT markers (AKT2, PI3KCAd or TWIST1) were expressed. For tumor tissue, an aberrant PI3KCA pathway was defined as positive if a PI3KCA mutation, PTEN loss, pAKT positivity and/or positive ALDH1 staining was detected. As presented in Table IV, 20 pts had aberrant PI3KCA signaling in tumor tissues and CTCs, 18 pts had normal signaling in both, while 21 pts exhibited aberrant PI3KCA signaling only in the tumor tissue and 31 pts exhibited aberrant PI3KCA signaling only in CTCs. No significant association was observed between aberrant PI3KCA signaling in tissue and CTCs $(\mathrm{P}=0.167)$. 


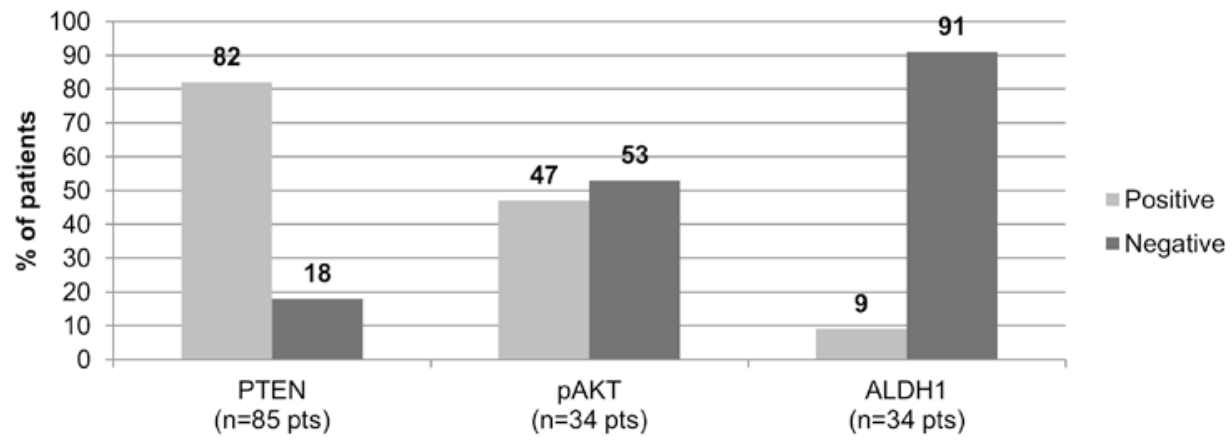

Figure 3. Expression of EMT and stem cell markers in tumor tissue. A PTEN loss was detected in $18 \%$ of pts, and positive pAKT and ALDH1 staining was observed in 47 and $9 \%$ of pts, respectively. Pts, patients; PTEN, phosphatase and tensin homolog; pAKT, phosphorylated AKT serine/threonine kinase; ALDH1, aldehyde dehydrogenase 1 family member A1.

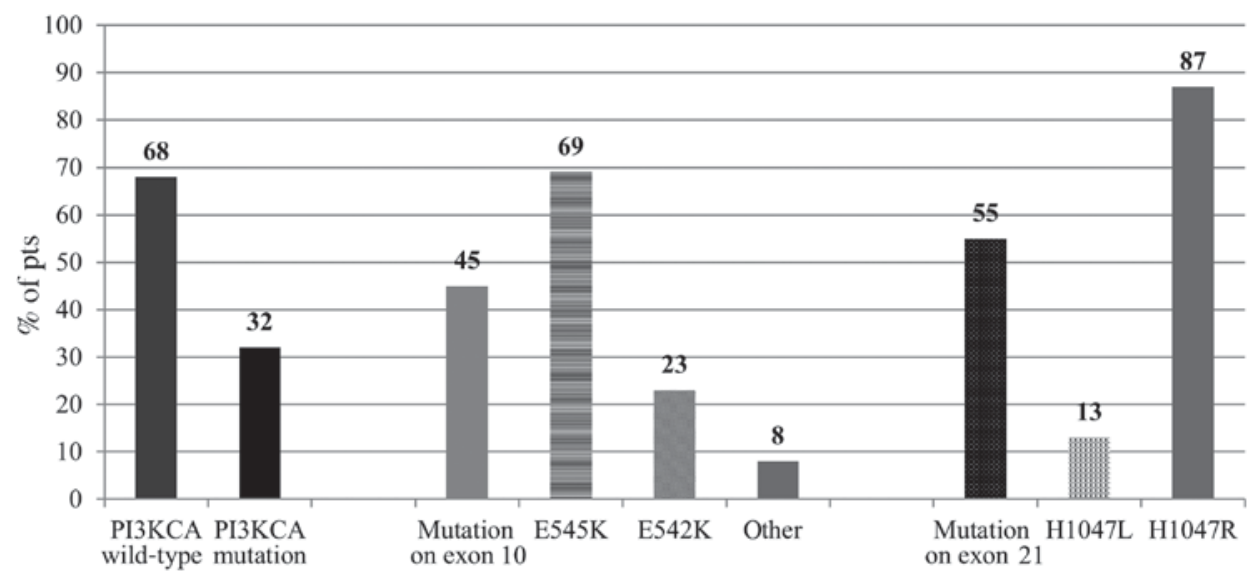

PI3KCA mutation

Figure 4. PI3KCA mutation analysis in tumor tissue (n=90 pts). PI3KCA mutations were detected in $3 \%$ of pts, most frequently identified on exon 21 (55\%) and exon 10 (45\%). Pts, patients; PI3KCA, phosphatidylinositol 3-kinase.

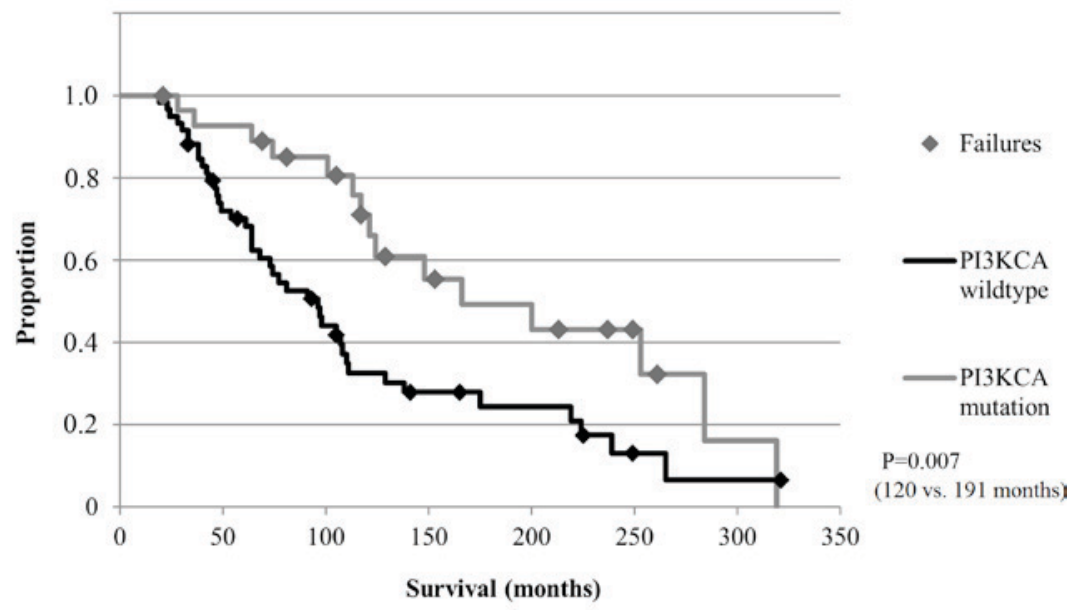

Figure 5. OS of pts harboring PI3KCA mutations in the tumor tissue ( $\mathrm{n}=90 \mathrm{pts})$. Pts harboring a PI3KCA mutation had a significantly longer OS compared with pts with wild-type PI3KCA in their tumor tissue (120 months vs. 191 months; P=0.007). PI3KCA, phosphatidylinositol 3-kinase; OS, overall survival; pts, patients.

Correlation of the ER status of the primary tumor with aberrant PI3KCA signaling. Notably, the majority of pts with a detectable PI3KCA mutation had an ER-positive primary tumor (25 pts; $86 \%$ ), however this association was not statistically significant
( $\mathrm{P}=0.527)$. Only 3 pts with mutated PI3KCA were ER-negative in their primary tumor (10\%). A total of 47 pts with wild-type PI3KCA had an ER-positive primary tumor (77\%) and nine pts were ER-negative (15\%) (data not shown). Furthermore, 
Table III. Association of ALDH1 expression in tumor tissue and the presence of slCTCs. Number of pts with each tumor tissue ALDH1 status and positive/negative for slCTCs.

\begin{tabular}{lcc}
\hline \multirow{2}{*}{$\begin{array}{l}\text { Tumor tissue } \\
\text { ALDH1 status }\end{array}$} & \multicolumn{2}{c}{ slCTC presence } \\
\cline { 2 - 3 } & 23 & slCTCs- \\
\hline ALDH1- & 1 & 2 \\
ALDH1+ & & 8 \\
\hline $\mathrm{n}=34$ pts; statistical analysis with contingency tables (Fisher`s exact \\
test) did not show a significant correlation between ALDH1 status \\
of tumor tissue and the presence of slCTCs in the same pts P=0.200. \\
ALDH1, aldehyde dehydrogenase 1 family member A1; slCTCs, \\
stemness-like circulating tumor cells; pts, patients. \\
\hline
\end{tabular}

Table IV. Comparison of PI3KCA pathway activation in CTCs and tumor tissue. Number of pts with normal or aberrant PI3KCA signaling in tissue and CTCs.

\begin{tabular}{lcc}
\hline & \multicolumn{2}{c}{ CTCs } \\
\cline { 2 - 3 } Tumor & Normal & Aberrant \\
tissue & PI3KCA & PI3KCA \\
signaling & signaling \\
\hline Normal PI3KCA signaling & 18 & 31 \\
Aberrant PI3KCA signaling & 21 & 20 \\
\hline
\end{tabular}

$\mathrm{n}=90 \mathrm{pts}$; Statistical analysis with contingency tables $\left(\chi^{2}\right.$ square test $)$ did not show a significant correlation between the PI3KCA signaling in tumor tissue and in CTC of the same pts $\mathrm{P}=0.167$. PI3KCA, phosphatidylinositol 3-kinase; CTCs, circulating tumor cells; pts, patients.

the present study identified no significant association between a PTEN loss and an ER-positive primary tumor $(\mathrm{P}=0.969)$. Aberrant PI3KCA signaling in tumor tissue, as revealed by PTEN loss and/or a PI3KCA mutation, was not significantly associated with the ER status of the primary tumor $(\mathrm{P}=0.825)$. Furthermore, no association was observed between the ER status of the primary tumor and the expression of PI3KCA in CTCs $(\mathrm{P}=0.163)$, or the presence of slCTCs, exclusively $(\mathrm{P}=0.425)$. By contrast, the ER status of the primary tumor was significantly associated with the presence of slCTCs and/or PI3KCA expressing CTCs ( $\mathrm{P}=0.015$; Table V).

Association of obtained results with OS. The median follow-up time for the OS was 107 months (range, 21-321 months). Although no significant differences with regard to the OS were obtained for all CTCs subgroups or the expression of EMT and stem cell markers in tumor tissue (Table VI), pts with detectable PI3KCA mutations in tumor tissue had a significantly longer OS compared with pts with wild-type PI3KCA expression ( $\mathrm{P}=0.007$; Fig. 5). In addition, pts with aberrant PI3KCA signaling in CTCs and/or aberrant signaling in cancerous tissue had a significantly longer OS compared with pts with normal PI3KCA signaling ( $\mathrm{P}=0.009$; Fig. 6).
Table V. Association of the ER status of the primary breast tumor with aberrant PI3KCA signaling and other markers.

\begin{tabular}{|c|c|c|}
\hline Tumor characteristic & $\mathrm{n}$ & $\begin{array}{c}\text { P-value } \\
\left(\chi^{2} \text { square or }\right. \\
\text { Fisher's } \\
\text { exact test })\end{array}$ \\
\hline PI3KCA $\alpha+$ CTCs vs. ER status & 85 & 0.163 \\
\hline $\begin{array}{l}\text { PI3KCA mutation in tumor tissue vs. } \\
\text { ER status }\end{array}$ & 85 & 0.527 \\
\hline $\begin{array}{l}\text { PTEN loss in tumor tissue vs. } \\
\text { ER status }\end{array}$ & 80 & 0.969 \\
\hline $\begin{array}{l}\text { PTEN loss and/or PI3KCA mutation } \\
\text { in tumor tissue vs. ER status }\end{array}$ & 85 & 0.825 \\
\hline $\begin{array}{l}\text { slCTCs and/or CTCs in EMT vs. } \\
\text { ER status }\end{array}$ & 85 & 0.015 \\
\hline slCTCs vs. ER status & 85 & 0.425 \\
\hline
\end{tabular}

Statistical analysis with contingency tables did not show a significant correlation between the ER status of the primary tumor and aberrant PI3KCA signaling in CTCs or tumor tissue except for the presence of slCTCs and/or CTCs in EMT. ER, estrogen receptor; PI3KCA, phosphatidylinositol 3-kinase; CTCs, circulating tumor cells; PTEN, phosphatase and tensin homolog; slCTCs, stemness-like CTCs; EMT, epithelial-mesenchymal transition; pts, patients.

\section{Discussion}

In the current study, CTCs in EMT and/or slCTCs were detected in $50 \%$ of the pts involved in the study, with a significant association demonstrated for $\mathrm{pAKT}$ expression in cancerous tissue and AKT2 expression in CTCs. PI3KCA hotspot mutations in tumor tissue were frequently identified and associated with a prolonged OS. Furthermore, aberrant PI3KCA signaling in tumor tissue and/or CTCs had a positive impact on the OS of patients. slCTCs and CTCs in EMT, alone or together, have previously been identified in the heterogeneous population of CTCs in metastatic BC pts by our group and others (20-22,24,33,34). Furthermore, CTCs exhibiting features of EMT were demonstrated to be associated with a worse prognosis (35). Furthermore, EMT may be associated with the acquisition of stemness-like properties (36) and certain studies have indicated that stem cell-like cells may exist in a convertible EMT state to promote therapeutic resistance (37-39). Mego et al (40) analyzed the primary tumor and CTCs of 102 early BC pts, and did not find any association between the expression of EMT initiating transcription factors in tissue, TWIST and snail family transcriptional repressor 2 (SLUG), and the presence of CTCs (40). These results are consistent with the results of the present study, established for metastatic BC pts. Mego et al (40) detected CTCs in $24.5 \%$ of primary BC pts, whereas $8.8 \%$ exhibited expression of epithelial marker keratin 19, and $12.8 \%$ exhibited expression of EMT markers (TWIST, snail family transcriptional repressor 1, SLUG, forkhead box $\mathrm{C} 2$ and zinc finger E-box binding homeobox 1). The study also demonstrated co-expression of epithelial and EMT markers in $2.9 \%$ of pts. In the present 
Table VI. Expression of EMT and stem cell markers in CTCs and tumor tissue with regard to the OS.

\begin{tabular}{lcc}
\hline Marker & & $\begin{array}{c}\text { P-value for } \\
\text { association } \\
\text { with OS }\end{array}$ \\
\hline CTCs & $\mathrm{n}$ & \\
sICTCs & 90 & 0.794 \\
CTCs in EMT & 90 & 0.063 \\
AKT2+ CTCs & 90 & 0.177 \\
PI3KCA + CTCs & 57 & 0.177 \\
TWIST1+ CTCs & 57 & 0.812 \\
Presence of EMT and/or slCTCs & 57 & 0.101 \\
Presence of EMT and slCTCs & 90 & 0.966 \\
Tumor tissue & & \\
pAKT+ tumor tissue & 19 & 0.507 \\
ALDH1+ tumor tissue & 19 & 0.597 \\
PTEN loss in tumor tissue & 83 & 0.054 \\
PI3KCA mutation in tumor tissue & $\mathbf{5 7}$ & $\mathbf{0 . 0 0 7}$ \\
PI3KCA mutation and/or PTEN loss & 57 & 0.166 \\
CTCs and/or tumor tissue & & \\
Aberrant PI3KCA signaling in & $\mathbf{5 7}$ & $\mathbf{0 . 0 0 9}$ \\
CTCs and/or tumor tissue & & \\
ALDH1+ in CTCs and/or tumor & 57 & 0.899 \\
tissue & & \\
PI3KCA + +mutated in CTCs and/or & 57 & 0.760 \\
tumor tissue & & \\
AKT2+/pAKT+ in CTCs and/or & 57 & 0.234 \\
tumor tissue & & \\
\hline
\end{tabular}

Statistical analysis with Kaplan Meier estimator did not show a significant correlation between markers of the PI3KCA pathway in regard to the OS except for aberrant PI3KCA signaling in CTCs and/or tumor tissue. EMT, epithelial-mesenchymal transition; CTCs, circulating tumor cells; OS, overall survival; slCTCs, stemness-like CTCs; AKT2, AKT serine/threonine kinase 2; PI3KCA, phosphatidylinositol 3-kinase; TWIST1, twist family bHLH transcription factor 1; pAKT, phosphorylated AKT; ALDH1, aldehyde dehydrogenase 1 family member A1; PTEN, phosphatase and tensin homolog.

study, CTCs in EMT were observed in $56 \%$ of pts. Of those $56 \%$, only $2 \%$ exhibited expression of TWIST1. By contrast, something that was not investigated by Mego et al (40), the majority of pts exhibited expression of PI3KCA $\alpha$ (42\%) or AKT2 (44\%). Furthermore, the present study did not compare the presence of epithelial CTCs and CTCs in EMT. However, the coexistence of slCTCs and CTCs in EMT was investigated and was observed in $22 \%$ of pts. Other than the expression of pAKT in tumor tissue and AKT2 expression in CTCs, no significant association was demonstrated. Within the PI3KCA-AKT pathway, pAKT was already known to be associated with a mesenchymal phenotype, and studies hypothesized its contribution to therapy resistance based on its function in apoptosis attenuation and, consequently, in enhanced cell proliferation and metastatic spread (41-43). Frequently implicated mechanisms of abnormal pAKT activation include PI3KCA mutations, amplification of the AKT gene and PTEN mutation or loss $(44,45)$. In the current study, pAKT expression was observed in $47 \%$ of pts, but was not associated with the presence of PI3KCA mutations, which is consistent with an analysis of more than 500 primary breast tumors (46). Furthermore, phosphorylation of AKT was observed significantly more often in tumors with low PTEN expression and HER2 enriched BC subtypes as demonstrated in studies that included over $500 \mathrm{BC}$ pts $(46,47)$. The results of the present study demonstrated no significant association between pAKT and PTEN loss. The separation of different BC subtypes was not possible within the current study due to the small patient cohort size and the heterogeneity of the group. Loss or downregulation of PTEN is frequently observed in $\mathrm{BC}$, with a PTEN loss in $30 \%$ of cases, which is comparable with the results of the current study $(46,48)$. Notably, no pts exhibited PTEN loss and a simultaneously occurring PI3KCA mutation, which is consistent with the results of a study by Saal et al (49), which demonstrated that the coexistence of PTEN loss and PI3KCA mutations is rare. PI3KCA mutations are frequently detected in breast tumors, the hotspot mutation $\mathrm{H} 1047 \mathrm{R}$ on exon 21 has detection rates of up to $55 \%$, which is comparable to the results of the present study as PI3KCA mutations were detected in 55\% of the pts (50). For the hotspot mutations on exon 10 (E454K and E424K mutation), the current study observed higher mutational rates (45\%) compared to the previously published studies, which reported a frequency of $20 \%$ for E545K and $~ 11 \%$ for E542K (50). Depending on the methods used, PI3KCA mutations are reported to occur in $20-40 \%$, with an average of $26 \%$, in BC pts, as reported in a review by Karakas et al (51). Saal et al (49) detected PI3KCA mutations in 26.4\%, Buttittata et al (52) and Karakas et al (51) in $23.5 \%$, Bachmann et al (53) in 21.4\%, Levine et al (54) in $18.1 \%$, Campbell et al (55) in 40\%, Wu et al (56) in $20.6 \%$, Samuels et al (57) in $8.3 \%$ and Lee et al (58) in $26.9 \%$ of BC pts. Perez-Torinio et al (9) reported PI3KCA mutations in $24 \%$ of pts, with the majority located on exon 21 (13\%) and exon 10 (11\%). Certain groups, including Stemke-Hale et al (46), demonstrated that PI3KCA mutations were frequently detected in hormone receptor-positive pts (34.5\%). Other studies have already demonstrated an association between the activation of the PI3KCA-AKT signaling pathway and cancer stem cells with ALDH1 as a marker, which is known to be associated with a stem cell-like phenotype, and enables invasiveness and metastatic progression $(59,60)$. The current study detected expression of ALDH1 in 9\% of pts, which is comparable with the results published by Theodropoulos et al (21), who identified that $17.7 \%$ of the CTCs analyzed in seven metastatic BC pts expressed ALDH1 (high)/CD24 (-/low). The present study did not demonstrate a significant association between the presence of slCTCs or expression of ALDH1 in tissue, and markers of the PI3KCA signaling pathway. slCTCs were detected in $23 \%$ and ALDH1 expression was detected in $9 \%$ of pts, but were not associated with any other marker of investigation. When comparing the expression of EMT and stem cell marker genes in CTCs and cancerous tissue, the present study only demonstrated a significant association for AKT; positive expression of pAKT in cancerous tissue was associated with AKT2 expression in CTCs. Although the expression of AKT in CTCs has already been demonstrated (61), a comparison of 


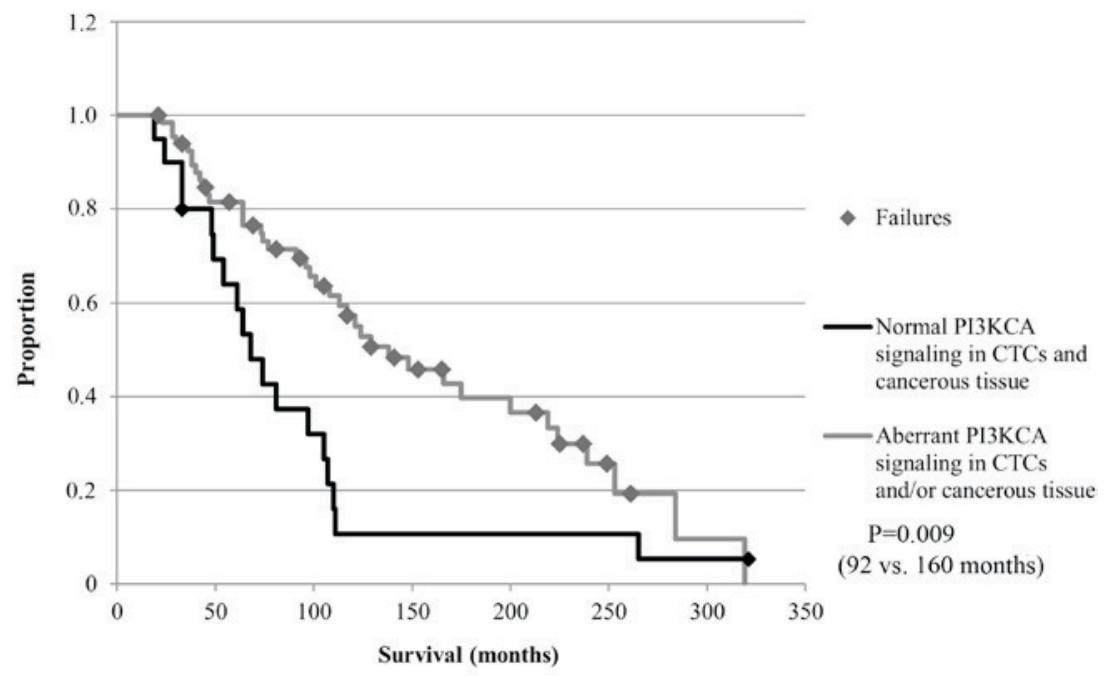

Figure 6. OS of pts with aberrant PI3KCA signaling in CTCs and/or tumor tissue (n=90 pts). Pts with aberrant PI3KCA signaling in CTCs and/or tumor tissue had a significantly longer OS compared with pts with normal PI3KCA signaling (92 months vs. 160 months; $\mathrm{P}=0.009)$. PI3KCA, phosphatidylinositol 3-kinase; CTCs, circulating tumor cells; OS, overall survival; pts, patients.

the expression of EMT and stem cell markers in CTCs and matched tumor tissue from MBC pts, to the best of our knowledge, has not been demonstrated comprehensively. While a generally concordant expression of PI3KCA and PTEN has been documented for primary tumor and distant metastasis (62-65), comparing CTCs and metastasis, a discordance in the PI3KCA mutational status was demonstrated (66). This discrepancy may be explained by a study by Markou et al (67), which indicated that the PI3KCA status may change during disease progression (67). In the present study, the experimental design did not enable the investigation of PI3KCA mutations in CTCs, which may explain why no association between CTCs and tumor tissue was identified. Within the current study, different CTCs phenotypes, and the expression of EMT and stem cell markers in tumor tissue, were not associated with the OS. By contrast, pts with detectable PI3KCA mutations in tumor tissue or pts with aberrant PI3KCA signaling in CTCs and/or cancerous tissue had a significantly longer OS than pts with wild-type PI3KCA expression. Contradictory results regarding the influence of PI3KCA mutations on the OS have been previously reported. Certain groups have reported that PI3KCA mutations are an indicator of poor prognosis $(11,12,68)$, and others indicated a positive effect with regard to PFS and OS, supporting the results of the present study $(8-10,13,69)$. Similar, diverse results have also been reported for ALDH1 (70-75). The different results may be explained by the various treatment regimens of these pts. In this context, it was suggested that therapy benefit is more dependent on the ER status rather than on the PI3KCA mutation itself $(76,77)$. As reported in the literature, PI3KCA mutations are detected significantly more often in ER-positive pts $(64,78,79)$. Applying this idea to the results of the current study, it may be speculated that pts with PI3KCA mutations may have an improved OS due to the treatment received. The present study did not observe a significant association of ER status of the primary tumor with aberrant PI3KCA signaling in CTCs or tissue. The majority of pts (86\%) harboring a PI3KCA mutation had an ER-positive primary tumor, compared with $77 \%$ of pts with wild-type PI3KCA. Additionally, clinical studies have demonstrated an association between PI3KCA-AKT and ER signaling $(68,80)$. PI3K blockade enhanced the responsiveness to endocrine treatment and may augment this therapy regime in future (79). Currently, different PI3K pathway inhibitors are under investigation to treat metastatic BC pts accordingly (7). These inhibitors include pan-PI3K inhibitors (burpalisib), mTOR inhibitors (everolimus) and dual PI3K/mTOR inhibitors (BEZ 235 and BGT226) (81-83). In this regard, everolimus in combination with exemestane has been demonstrated to significantly improve the PFS in pts with advanced BC (15). Furthermore, pts harboring a PI3KCA mutation and/or PTEN loss had a significant longer PFS when treated with everolimus in the BOLERO-3 trial (18). Additionally, the BELLE-2 trial demonstrated the first promising results. Hormone receptor positive metastatic $\mathrm{BC}$ pts who had become resistant to endocrine treatment significantly benefitted from fulvestrant in combination with the PI3K inhibitor buparlisib (BKM120; Novartis) when a PI3KCA mutation detected in their ctDNA (84). In a group of pts with PI3KCA mutations identified by ctDNA during liquid biopsy, the overall response rate with fulvestrant and buparlisib was $18.4 \%$, compared with $3.5 \%$ with fulvestrant and placebo. In a group of pts with PI3K activation in archival tissue $(n=372)$, there was a trend toward an improvement in the PFS with buparlisib, however, it was not statistically significant. The median PFS was 6.8 and 4.0 months, for buparlisib and placebo, respectively (HR, 0.76; 95\% CI, 0.60-0.97; P=0.014) (19). Taken together, these results indicate that PI3KCA mutations may contribute to treatment resistance by triggering the PI3KCA pathway, and inhibiting this signaling may help to overcome acquired resistance.

In conclusion, the current study indicated that aberrant PI3KCA signaling in tumor tissue and/or CTCs was significantly associated with increased OS. Thus, using CTCs as a liquid biopsy for targeted therapy may complement or even replace tissue analysis, particularly when metastatic tissue is difficult to obtain. Furthermore, CTCs as a liquid biopsy may be a less invasive alternative for follow-up assessment of 
actionable targets implicated in the PI3KCA-AKT pathway. As a potential limitation of this study, a direct comparison between PI3KCA mutations in tumor tissue and CTCs could not be performed because of the method used for selection and detection of CTCs. However, the population of CTCs is very heterogeneous and it seems necessary to analyze a broad set of genes to identify individual therapeutic targets in the follow-up of the disease (85).

\section{Acknowledgements}

The authors highly value the assistance of Mrs. Gabriele Ladwig, Mrs. Elisabeth Jeske, Mrs. Fabiola Saballs, Mrs. Stefanie Richter, Mr. Thomas Hager and Mr. Karl Worm from the Institute of Pathology (University Hospital Essen, University of Duisburg-Essen) for support in tissue analysis. We further thank all scientific and medical employees that contributed to this work. Furthermore, we are grateful for the support of our nurses and all physicians for blood drawing (University Hospital Essen and University of Duisburg-Essen).

\section{References}

1. Foroni C, Broggini M, Generali D and Damia G: Epithelial-mesenchymal transition and breast cancer: Role, molecular mechanisms and clinical impact. Cancer Treat Rev 38: 689-697, 2012

2. McInnes LM, Jacobson N, Redfern A, Dowling A, Thompson EW and Saunders CM: Clinical implications of circulating tumor cells of breast cancer patients: Role of epithelial-mesenchymal plasticity. Front. Oncol 5: 42, 2015.

3. Wu Y, Sarkissyan M and Vadgama JV: Epithelial-mesenchymal transition and breast cancer. J Clin Med 5: E13, 2016.

4. Chalhoub $\mathrm{N}$ and Baker SJ: PTEN and the PI3-kinase pathway in cancer. Annu Rev Pathol 4: 127-150, 2009.

5. Dirican E, Akkiprik M and Özer A: Mutation distributions and clinical correlations of PIK3CA gene mutations in breast cancer. Tumour Biol 37: 7033-7045, 2016.

6. Thorpe LM, Yuzugullu H and Zhao JJ: PI3K in cancer: Divergent roles of isoforms, modes of activation and therapeutic targeting. Nat Rev Cancer 15: 7-24, 2015.

7. Mayer IA and Arteaga CL: The PI3K/AKT pathway as a target for cancer treatment. Annu Rev Med 67: 11-28, 2016.

8. Maruyama N, Miyoshi Y, Taguchi T, Tamaki Y, Monden M and Noguchi S: Clinicopathologic analysis of breast cancers with PIK3CA mutations in Japanese women. Clin Cancer Res 13: 408-814, 2007.

9. Pérez-Tenorio G, Alkhori L, Olsson B, Waltersson MA, Nordenskjöld B, Rutqvist LE, Skoog L and Stål O: PIK3CA mutations and PTEN loss correlate with similar prognostic factors and are not mutually exclusive in breast cancer. Clin Cancer Res 13: 3577-3584, 2007.

10. Kalinsky K, Jacks LM, Heguy A, Patil S, Drobnjak M, Bhanot UK, Hedvat CV, Traina TA, Solit D, Gerald W and Moynahan ME: PIK3CA mutation associates with improved outcome in breast cancer. Clin Cancer Res 15: 5049-5059, 2009.

11. Li SY, Rong M, Grieu F and Iacopetta B: PIK3CA mutations in breast cancer are associated with poor outcome. Breast Cancer Res Treat 96: 91-95, 2006.

12. Hennessy BT, Gonzalez-Angulo AM, Stemke-Hale K, Gilcrease MZ, Krishnamurthy S, Lee JS, Fridlyand J, Sahin A, Agarwal R, Joy C, et al: Characterization of a naturally occurring breast cancer subset enriched in epithelial-to-mesenchymal transition and stem cell characteristics. Cancer Res 69: 4116-4124, 2009.

13. Cizkova M, Susini A, Vacher S, Cizeron-Clairac G, Andrieu C, Driouch K, Fourme E, Lidereau R and Bièche I: PIK3CA mutation impact on survival in breast cancer patients and in ER $\alpha, P R$ and ERBB2-based subgroups. Breast Cancer Res 14: R28, 2012.

14. Lee JJ, Loh K and Yap YS: PI3K/AKT/mTOR inhibitors in breast cancer. Cancer Biol Med 12: 342-354, 2015.
15. Baselga J, Campone M, Piccart M, Burris HA III, Rugo HS, Sahmoud T, Noguchi S, Gnant M, Pritchard KI, Lebrun F, et al: Everolimus in postmenopausal hormone-receptor-positive advanced breast cancer. N Engl J Med 366: 520-529, 2012.

16. André F, Hurvitz S, Fasolo A, Tseng LM, Jerusalem G, Wilks S, O'Regan R, Isaacs C, Toi M, Burris H, et al: Molecular alterations and everolimus efficacy in human epidermal growth factor receptor 2-overexpressing metastatic breast cancers: Combined exploratory biomarker analysis from BOLERO-1 and BOLERO-3. J Clin Oncol 34: 2115-2124, 2016.

17. Hurvitz SA, Andre F, Jiang Z, Shao Z, Mano MS, Neciosup SP, Tseng LM, Zhang Q, Shen K, Liu D, et al: Combination of everolimus with trastuzumab plus paclitaxel as first-line treatment for patients with HER2-positive advanced breast cancer (BOLERO-1): A phase 3, randomised, double-blind, multicentre trial. Lancet Oncol 16: 816-829, 2015.

18. André F, O'Regan R, Ozguroglu M, Toi M, Xu B, Jerusalem G, Masuda N, Wilks S, Arena F, Isaacs C, et al: Everolimus for women with trastuzumab-resistant, HER2-positive, advanced breast cancer (BOLERO-3): A randomised, double-blind, placebo-controlled phase 3 trial. Lancet Oncol 15: 580-591, 2014.

19. Baselga J, Im SA, Iwata H, Clemons M, Ito Y, Awada A, Chia S, Jagiello-Gruszfeld A, Pistilli B, Tseng LM, et al: The phase III BELLE-2 trial. San Antonio breast cancer symposium. Abstract S6-01, Presented December, 2015.

20. Aktas B, Tewes M, Fehm T, Hauch S, Kimmig R and Kasimir-Bauer S: Stem cell and epithelial-mesenchymal transition markers are frequently overexpressed in circulating tumor cells of metastatic breast cancer patients. Breast Cancer Res 11: R46, 2009.

21. Theodoropoulos PA, Polioudaki H, Agelaki S, Kallergi G, Saridaki Z, Mavroudis D and Georgoulias V: Circulating tumor cells with a putative stem cell phenotype in peripheral blood of patients with breast cancer. Cancer Lett 288: 99-106, 2010.

22. Kallergi G, Papadaki MA, Politaki E, Mavroudis D, Georgoulias V and Agelaki S: Epithelial to mesenchymal transition markers expressed in circulating tumour cells of early and metastatic breast cancer patients. Breast Cancer Res 13: R59, 2011.

23. Kasimir-Bauer S, Hoffmann O, Wallwiener D, Kimmig R and Fehm T: Expression of stem cell and epithelial-mesenchymal transition markers in primary breast cancer patients with circulating tumor cells. Breast Cancer Res 14: R15, 2012.

24. Papadaki MA, Kallergi G, Zafeiriou Z, Manouras L, Theodoropoulos PA, Mavroudis D, Georgoulias V and Agelaki S: Co-expression of putative stemness and epithelial-to-mesenchymal transition markers on single circulating tumour cells from patients with early and metastatic breast cancer. BMC Cancer 14: 651, 2014.

25. Krawczyk N, Meier-Stiegen F, Banys M, Neubauer H, Ruckhaeberle E and Fehm T: Expression of stem cell and epithelial-mesenchymal transition markers in circulating tumor cells of breast cancer patients. Biomed Res Int 2014: 415721, 2014.

26. Giordano A, Gao H, Anfossi S, Cohen E, Mego M, Lee BN, Tin S, De Laurentiis M, Parker CA, Alvarez RH, et al: Epithelial-mesenchymal transition and stem cell markers in patients with HER2-positive metastatic breast cancer. Mol Cancer Ther 11: 2526-2534, 2012.

27. Hayes DF, Walker TM, Singh B, Vitetta ES, Uhr JW, Gross S, Rao C, Doyle GV and Terstappen LW: Monitoring expression of HER-2 on circulating epithelial cells in patients with advanced breast cancer. Int J Oncol 21: 1111-1117, 2002.

28. Generali D, Fox SB, Brizzi MP, Allevi G, Bonardi S, Aguggini S, Milani M,Bersiga A, Campo L, Dionisio R, etal: Down-regulation of phosphatidylinositol 3'-kinase/AKT/molecular target of rapamycin metabolic pathway by primary letrozole-based therapy in human breast cancer. Clin Cancer Res 14: 2673-2680, 2008.

29. McCubrey JA, Sokolosky ML, Lehmann BD, Taylor JR, Navolanic PM, Chappell WH, Abrams SL, Stadelman KM, Wong EW, Misaghian N, et al: Alteration of Akt activity increases chemotherapeutic drug and hormonal resistance in breast cancer yet confers an achilles heel by sensitization to targeted therapy. Adv Enzyme Regul 48: 113-135, 2008.

30. Droog M, Beelen K, Linn S and Zwart W: Tamoxifen resistance: From bench to bedside. Eur J Pharmacol 717: 47-57, 2013.

31. Oken MM, Creech RH, Tormey DC, Horton J, Davis TE, McFadden ET and Carbone PP: Toxicity and response criteria of the eastern cooperative oncology group. Am J Clin Oncol 5: 649-655, 1982 . 
32. McCarty KS Jr, Miller LS, Cox EB, Konrath J and McCarty KS Sr: Estrogen receptor analyses. Correlation of biochemical and immunohistochemical methods using monoclonal antireceptor antibodies Arch Pathol Lab Med 109: 716-721, 1985.

33. Raimondi C, Gradilone A, Naso G, Vincenzi B, Petracca A, Nicolazzo C, Palazzo A, Saltarelli R, Spremberg F, Cortesi E and Gazzaniga P: Epithelial-mesenchymal transition and stemness features in circulating tumor cells from breast cancer patients. Breast Cancer Res Treat 130: 449-455, 2011.

34. Polioudaki H, Agelaki S, Chiotaki R, Politaki E, Mavroudis D, Matikas A, Georgoulias V and Theodoropoulos PA: Variable expression levels of keratin and vimentin reveal differential EMT status of circulating tumor cells and correlation with clinical characteristics and outcome of patients with metastatic breast cancer. BMC Cancer 15: 399, 2015.

35. Bulfoni M, Gerratana L, Del Ben F, Marzinotto S, Sorrentino M, Turetta M, Scoles G, Toffoletto B, Isola M, Beltrami CA, et al: In patients with metastatic breast cancer the identification of circulating tumor cells in epithelial-to-mesenchymal transition is associated with a poor prognosis. Breast Cancer Res 18: 30 , 2016.

36. Mani SA, Guo W, Liao MJ, Eaton EN, Ayyanan A, Zhou AY, Brooks M, Reinhard F, Zhang CC, Shipitsin M, et al: The epithelial-mesenchymal transition generates cells with properties of stem cells. Cell 133: 704-715, 2008

37. Luo M, Brooks M and Wicha MS: Epithelial-mesenchymal plasticity of breast cancer stem cells: Implications for metastasis and therapeutic resistance. Curr Pharm Des 21: 1301-1310, 2015.

38. Yu M, Bardia A, Wittner BS, Stott SL, Smas ME, Ting DT, Isakoff SJ, Ciciliano JC, Wells MN, Shah AM, et al: Circulating breast tumor cells exhibit dynamic changes in epithelial and mesenchymal composition. Science 339: 580-581, 2013.

39. Creighton CJ, Li X, Landis M, Dixon JM, Neumeister VM, Sjolund A, Rimm DL, Wong $H$, Rodriguez A Herschkowitz JI, et al: Residual breast cancers after conventional therapy display mesenchymal as well as tumor-initiating features Proc Natl Acad Sci USA 106: 13820-13825, 2009.

40. Mego M, Cierna Z, Janega P, Karaba M, Minarik G, Benca J Sedlácková T, Sieberova G, Gronesova P, Manasova D, et al: Relationship between circulating tumor cells and epithelial to mesenchymal transition in early breast cancer. BMC Cancer 15 $533,2015$.

41. Carmona FJ, Montemurro F, Kannan S, Rossi V, Verma C, Baselga $\mathbf{J}$ and Scaltriti M: AKT signaling in ERBB2-amplified breast cancer. Pharmacol Ther 158: 63-70, 2016.

42. Nahta R: Pharmacological strategies to overcome HER2 cross-talk and Trastuzumab resistance. Curr Med Chem 19: 1065-1075, 2012

43. Dillon RL, Marcotte R, Hennessy BT, Woodgett JR, Mills GB and Muller WJ: Akt1 and Akt2 play distinct roles in the initiation and metastatic phases of mammary tumor progression. Cancer Res 69: 5057-5064, 2009

44. Wickenden JA and Watson CJ: Key signaling nodes in mammary gland development and cancer. Signalling downstream of PI3Kinase in mammary epithelium: A play in 3 Akts. Breast Cancer Res 12: 202, 2010.

45. Miller TW, Forbes JT, Shah C, Wyatt SK, Manning HC, Olivares MG, Sanchez V, Dugger TC, de Matos Granja N, Narasanna A, et al: Inhibition of mammalian target of rapamycin is required for optimal antitumor effect of HER2 inhibitors against HER2-overexpressing cancer cells. Clin Cancer Res 15: 7266-7276, 2009.

46. Stemke-Hale K, Gonzalez-Angulo AM, Lluch A, Neve RM, Kuo WL, Davies M, Carey M, Hu Z, Guan Y, Sahin A, et al: An integrative genomic and proteomic analysis of PIK3CA, PTEN, and AKT mutations in breast cancer. Cancer Res 68: 6084-6091, 2008

47. Cancer Genome Atlas Network: Comprehensive molecular portraits of human breast tumours. Nature 490: 61-70, 2012

48. Hennessy BT, Smith DL, Ram PT, Lu Y and Mills GB: Exploiting the PI3K/AKT pathway for cancer drug discovery. Nat Rev Drug Discov 4: 988-1004, 2005.

49. Saal LH, Holm K, Maurer M, Memeo L, Su T, Wang X, Yu JS, Malmström PO, Mansukhani M, Enoksson J, et al: PIK3CA mutations correlate with hormone receptors, node metastasis, and ERBB2 and are mutually exclusive with PTEN loss in human breast carcinoma. Cancer Res 65: 2554-2559, 2005.

50. www.mycancergenome.org/content/disease/breast-cancer/pik3ca (accessed 18 January 2017)
51. Karakas B, Bachman KE and Park BH: Mutation of the PIK3CA oncogene in human cancers. Br J Cancer 94: 455-459, 2006

52. Buttitta F, Felicioni L, Barassi F, Martella C, Paolizzi D, Fresu G, Salvatore S, Cuccurullo F, Mezzetti A, Campani D and Marchetti A: PIK3CA mutation and histological type in breast carcinoma: High frequency of mutations in lobular carcinoma. J Pathol 208: 350-355, 2006.

53. Bachmann KE, Argani P, Samuels Y, Silliman N, Ptak J, Szabo S, Konishi H, Karakas B, Blair BG, Lin C, et al: The PIK3CA gene is mutated with high frequency in human cancers. Cancer Biol Ther 3: 772-775, 2004.

54. Levine DA, Bogomolniy F, Yee CJ, Lash A, Barakat RR, Borgen PI and Boyd J: Frequent mutation of the PIK3CA gene in ovarian and breast cancers. Clin Cancer Res 11: 2875-2878, 2005.

55. Campbell IG, Russell SE, Choong DY, Montgomery KG, Ciavarella ML, Hooi CS, Cristiano BE, Pearson RB and Phillips WA: Mutation of the PIK3CA gene in ovarian and breast cancer. Cancer Res 64: 7678-7681, 2004.

56. Wu G, Xing M, Mambo E, Huang X, Liu J, Guo Z, Chatterjee A, Goldenberg D, Gollin SM, Sukumar S, et al: Somatic mutation and gain of copy number of PIK3CA in human breast cancer. Breast Cancer Res 7: R609-R616, 2005.

57. Samuels Y, Wang Z, Bardelli A, Silliman N, Ptak J, Szabo S, Yan H, Gazdar A, Powell SM, Riggins GJ, et al: High frequency of mutations of the PIK3CA gene in human cancers. Science 304: 554, 2004.

58. Lee JW, Soung YH, Kim SY, Lee HW, Park WS, Nam SW, Kim SH, Lee JY, Yoo NJ and Lee SH: PIK3CA gene is frequently mutated in breast carcinomas and hepatocellular carcinomas. Oncogene 24: 1477-1480, 2005.

59. Tomita H, Tanaka K, Tanaka T and Hara A: Aldehyde dehydrogenase 1A1 in stem cells and cancer. Oncotarget 7: 11018-11032, 2016

60. Charafe-Jauffret E, Ginestier C, Iovino F, Tarpin C, Diebel M, Esterni B, Houvenaeghel G, Extra JM, Bertucci F, Jacquemier J, et al: Aldehyde dehydrogenase 1-positive cancer stem cells mediate metastasis and poor clinical outcome in inflammatory breast cancer. Clin Cancer Res 16: 45-55, 2010.

61. Kallergi G, Agelaki S, Kalykaki A, Stournaras C, Mavroudis D and Georgoulias V: Phosphorylated EGFR and PI3K/Akt signaling kinases are expressed in circulating tumor cells of breast cancer patients. Breast Cancer Res 10: R80, 2008.

62. Schleifman EB, Desai R, Spoerke JM, Xiao Y, Wong C, Abbas I, O'Brien C, Patel R, Sumiyoshi T, Fu L, et al: Targeted biomarker profiling of matched primary and metastatic estrogen receptor positive breast cancers. PLoS One 9: e88401, 2014.

63. Gonzalez-Angulo AM, Ferrer-Lozano J, Stemke-Hale K, Sahin A, Liu S, Barrera JA, Burgues O, Lluch AM, Chen H, Hortobagyi GN, et al: PI3K pathway mutations and PTEN levels in primary and metastatic breast cancer. Mol Cancer Ther 10: 1093-1101, 2011

64. Kalinsky K, Heguy A, Bhanot UK, Patil S and Moynahan ME: PIK3CA mutations rarely demonstrate genotypic intratumoral heterogeneity and are selected for in breast cancer progression. Breast Cancer Res Treat 129: 635-643, 2011.

65. Weigelt B, Glas AM, Wessels LF, Witteveen AT, Peterse JL and van't Veer LJ: Gene expression profiles of primary breast tumors maintained in distant metastases. Proc Natl Acad Sci USA 100: 15901-15905, 2003.

66. Deng G, Krishnakumar S, Powell AA, Zhang H, Mindrinos MN Telli ML, Davis RW and Jeffrey SS: Single cell mutational analysis of PIK3CA in circulating tumor cells and metastases in breast cancer reveals heterogeneity, discordance, and mutation persistence in cultured disseminated tumor cells from bone marrow. BMC Cancer 14: 456, 2014

67. Markou A, Farkona S, Schiza C, Efstathiou T, Kounelis S, Malamos N, Georgoulias V and Lianidou E: PIK3CA mutational status in circulating tumor cells can change during disease recurrence or progression in patients with breast cancer. Clin Cancer Res 20: 5823-5834, 2014.

68. Mangone FR, Bobrovnitchaia IG, Salaorni S, Manuli E and Nagai MA: PIK3CA exon 20 mutations are associated with poor prognosis in breast cancer patients. Clinics (Sao Paulo) 67: 1285-1290, 2012.

69. Loi S, Haibe-Kains B, Majjaj S, Lallemand F, Durbecq V, Larsimont D, Gonzalez-Angulo AM, Pusztai L, Symmans WF, Bardelli A, et al: PIK3CA mutations associated with gene signature of low mTORC1 signaling and better outcomes in estrogen receptor-positive breast cancer. Proc Natl Acad Sci USA 107: 10208-10213, 2010. 
70. Ginestier C, Hur MH, Charafe-Jauffret E, Monville F, Dutcher J, Brown M, Jacquemier J, Viens P, Kleer CG, Liu S, et al: ALDH1 Is a marker of normal and malignant human mammary stem cells and a predictor of poor clinical outcome. Cell Stem Cell 1: $555-567,2007$.

71. Morimoto K, Kim SJ, Tanei T, Shimazu K, Tanji Y, Taguchi T, Tamaki Y, Terada N and Noguchi S: Stem cell marker aldehyde dehydrogenase 1-positive breast cancers are characterized by negative estrogen receptor, positive human epidermal growth factor receptor type 2, and high Ki67 expression. Cancer Sci 100: 1062-1068, 2009.

72. Liu S, Cong Y, Wang D, Sun Y, Deng L, Liu Y, Martin-Trevino R, Shang L, McDermott SP, Landis MD, et al: Breast cancer stem cells transition between epithelial and mesenchymal states reflective of their normal counterparts. Stem Cell Reports 2: 78-91, 2013.

73. Resetkova E, Reis-Filho JS, Jain RK, Mehta R, Thorat MA, Nakshatri $\mathrm{H}$ and Badve S: Prognostic impact of ALDH1 in breast cancer: A story of stem cells and tumor microenvironment. Breast Cancer Res Treat 123: 97-108, 2010.

74. Zhong Y, Lin Y, Shen S, Zhou Y, Mao F, Guan J and Sun Q: Expression of ALDH1 in breast invasive ductal carcinoma: An independent predictor of early tumor relapse. Cancer Cell Int 13: 60, 2013.

75. Zhong Y, Shen S, Zhou Y, Mao F, Guan J, Lin Y, Xu Y and Sun Q: ALDH1 is a better clinical indicator for relapse of invasive ductal breast cancer than the CD44+/CD24-phenotype. Med Oncol 31: 864, 2014.

76. Zardavas D, Marvelde LT, Milne R, Joensuu H, Moynahan ME, Hennessy B, Bieche I, Saal LH, Stal O, Iacopetta B, et al: Tumor PIK3CA genotype and prognosis: A pooled analysis of 4,241 patients with early-stage breast cancer (BC). ASCO Annual Meeting, 2015.

77. Mayer IA, Abramson VG, Isakoff SJ, Forero A, Balko JM, Kuba MG, Sanders ME, Yap JT, Van den Abbeele AD Li Y, et al: Stand up to cancer phase Ib study of pan-phosphoinositide-3-kinase inhibitor buparlisib with letrozole in estrogen receptor-positive/human epidermal growth factor receptor 2-negative metastatic breast cancer. J Clin Oncol 32: 1202-1209, 2014.
78. Dunlap J, Le C, Shukla A, Patterson J, Presnell A, Heinrich MC, Corless CL and Troxell ML: Phosphatidylinositol-3-kinase and AKT1 mutations occur early in breast carcinoma. Breast Cancer Res Treat 120: 409-418, 2010.

79. Ciruelos Gil EM: Targeting the PI3K/AKT/mTOR pathway in estrogen receptor-positive breast cancer. Cancer Treat Rev 40: 862-871, 2014.

80. Campbell RA,Bhat-NakshatriP,PatelNM,Constantinidou D,AliS and Nakshatri H: Phosphatidylinositol 3-kinase/AKT-mediated activation of estrogen receptor alpha: A new model for anti-estrogen resistance. J Biol Chem 276: 9817-9824, 2001.

81. Ackermann TF, Hörtnagl H, Wolfer DP, Colacicco G, Sohr R, Lang F, Hellweg R and Lang UE: Phosphatidylinositide dependent kinase deficiency increases anxiety and decreases GABA and serotonin abundance in the amygdala. Cell Physiol Biochem 22: 735-744, 2008.

82. Kalkman HO: The role of the phosphatidylinositide 3-kinase-protein kinase B pathway in schizophrenia. Pharmacol Ther 110: 117-134, 2006.

83. Bendell JC, Rodon J, Burris HA, de Jonge M, Verweij J, Birle D, Demanse D, De Buck SS, Ru QC, Peters M, et al: Phase I, dose-escalation study of BKM120, an oral pan-Class I PI3K inhibitor, in patients with advanced solid tumors. J Clin Oncol 30: 282-290, 2012.

84. PI3K Inhibitor Improves PFS in BELLE-2 trial. Cancer Discov 6: 115-116, 2016.

85. Bredemeier M, Edimiris P, Tewes M, Mach P, Aktas B Schellbach D, Wagner J, Kimmig R and Kasimir-Bauer S: Establishment of a multimarker qPCR panel for the molecular characterization of circulating tumor cells in blood samples of metastatic breast cancer patients during the course of palliative treatment. Oncotarget 7: 41677-41690, 2016. 